\title{
Understanding Cash Sharing: A Sustainability Model
}

\author{
Leire San-Jose ${ }^{1,2, *} \mathbb{C}$, Ana Beraza ${ }^{1}$ and Jose Luis Retolaza ${ }^{3}$ \\ 1 Financial Economics II Department, ECRI, University of the Basque Country, UPV/EHU, 48940 Leioa, Spain; \\ ana.beraza@ehu.eus \\ 2 Department of Accountancy, Finance and Economics, University Huddersfield, Huddersfield HD1 3DH, UK \\ 3 Economics Department, University of Deusto, 48014 Bilbao, Spain; joseluis.retolaza@deusto.es \\ * Correspondence: leire.sanjose@ehu.eus; Tel.: +34-946013808
}

Received: 28 November 2018; Accepted: 15 March 2019; Published: 20 March 2019

\begin{abstract}
Traditionally, corporate treasury management has been strategically based on the idea of advancing collections and delaying payments, which has been regulated through the intermediation of financial entities using, for example, credit accounts. New technologies applied to the financial field facilitate direct interaction between companies and reduce the transaction costs, because they allow adjustment of the flows of needs, but high confidence is required. The current ease of access to credit does not promote the incorporation of new financial relationship systems, but the operation of these systems should be studied, since a future credit restriction, like that known in Europe at the end of the 2000s, could change the situation. The aim of this paper was to identify the factors involved in this relationship among companies and establish the main conditions for cash sharing between companies to achieve a successful financial function. The investigation is based on a Delphi analysis used to analyze the successful experiences of shared cash (Mondragon Corporation, Trocobuy, and Arboribus), the needed variables, and their context. Then, our model was created from that exploratory knowledge. Our model is called mutual cash holding and its relevance and reliability were contrasted using structural equations based on a questionnaire administered to financial managers of large- and medium-sized Spanish companies. The result generates knowledge that articulates a new collaborative tool that expands the possibilities for treasury management among companies.
\end{abstract}

Keywords: cash management; corporate sustainability finance; trust; transparency; collaboration

JEL Classification: D16; G30

\section{Introduction}

\subsection{Purpose}

Cash and cash equivalents have increased more than the double from 2006 to 2016 (Moodys US Corporate Cash Pile 2007). Some known companies hold large amounts of cash. For example, Apple held USD \$246 billion in their first quarter of 2017 (Duchin et al. 2017), and non-financial firms hold over USD $\$ 2$ trillion in cash and cash equivalents (Liu 2016). This amount is under-used by companies mostly due to the precautionary principle or future investment options (Duchin et al. 2017). Corporate social responsibility (CSR) does not impact company management directly, although it influences management of the companies' cash (Arouri and Pijourlet 2017; Cheung 2016). Regarding these disruptive opportunities generated by the FinTech revolution, the purpose of this paper was to identify the conditions under which it would be possible to develop a shared cash-holding system between businesses, customers, and suppliers, that would expand the possibilities of financing the working capital of the companies in a collaborative framework. The work is innovative in two aspects: (1) we 
identified a mechanism for financing purchase-sale operations that breaks with the logic of financial intermediation; (2) we analyzed the conditions of success in a possible collaborative relationship of payment and collection between clients and suppliers, a topic lacking in the literature.

\subsection{Literature Review}

Many studies have been published on the sharing economy. Some authors have contributed to the literature, as shown in Table 1 . The table based on the meta-analysis published by Ertz and Leblanc-Proulx (2018).

Table 1. Sharing economy literature review.

\begin{tabular}{|c|c|}
\hline Author(s) & Description/Conclusions \\
\hline (Belk 2014) & $\begin{array}{l}\text { Compared sharing and collaborative consumption and found that both are } \\
\text { growing in popularity today. }\end{array}$ \\
\hline Botsman and Rogers (2010) & Articulated, for the first time, the roots of collaborative consumption. \\
\hline $\begin{array}{l}\text { Schor and Fitzmaurice } \\
\text { (2014) }\end{array}$ & $\begin{array}{l}\text { Developed model represents an innovation capable of reallocating wealth } \\
\text { across the value chain, specifically away from middle actors and toward small } \\
\text { producers and consumers. }\end{array}$ \\
\hline Bardhi and Eckhardt (2012) & $\begin{array}{l}\text { Examined the nature of access in contrast to ownership and sharing, specifically } \\
\text { the consumer-object, consumer-consumer, and consumer-marketer } \\
\text { relationships. Six dimensions were identified to distinguish among the range of } \\
\text { access-based consumption scope. }\end{array}$ \\
\hline Hamari et al. (2016) & Investigates people's motivations to participate in Collaborative Consumption. \\
\hline Zervas et al. (2017) & $\begin{array}{l}\text { Analyzed Airbnb's entry into the state of Texas, USA and quantify its impact on } \\
\text { the Texas hotel industry over the subsequent decade. }\end{array}$ \\
\hline $\begin{array}{l}\text { John (2013); Lamberton } \\
\text { (2005) }\end{array}$ & $\begin{array}{l}\text { Explored the concept of sharing in three distinct spheres: Web 2.0, sharing } \\
\text { economies of production and consumption, and intimate interpersonal } \\
\text { relationships. }\end{array}$ \\
\hline $\begin{array}{l}\text { Lamberton and Rose (2012); } \\
\text { Lamberton (2005) }\end{array}$ & $\begin{array}{l}\text { Using three studies conceptualized commercial sharing systems within a } \\
\text { typology of shared goods and demonstrated the cost-related benefits of sharing. }\end{array}$ \\
\hline Shaheen and Cohen (2007) & $\begin{array}{l}\text { Cost savings, convenient locations, and guaranteed parking were identified as } \\
\text { the most common motivations for car sharing use worldwide, providing an } \\
\text { international comparison of car sharing operations, including similarities and } \\
\text { differences. }\end{array}$ \\
\hline Tussyadiah () & $\begin{array}{l}\text { The motivations that drive the use of peer-to-peer accommodation including } \\
\text { the societal aspects of sustainability and community, as well as economic } \\
\text { benefits. }\end{array}$ \\
\hline
\end{tabular}

Studies on cash holding provide evidence about the effect of determinants not included in the classical cash holding literature, such as transparency, CSR, and trust (Arouri and Pijourlet 2017; Cheung 2016), and these determinants favor the reduction of information asymmetries, as well as transaction and agency costs. We do not provide a review of classical literature because previous papers did not contribute directly to the sustainability literature (Cheung 2016). However, no clear conclusion exists about the relationship between these new factors about sustainability and the value of cash (Dudley and Zhang 2016; Liu 2016). In this paper, we contribute information for this problem as we establish the factors that determine a sustainable cash management model among companies. Then, the aim of this paper was to develop a collaborative and sustainable model for cash holding between companies in which the factors that permit mutual actions are explained. The situation involves companies reaching long-term consensual agreements of collaboration in the optimization of collections and payments, between two or more entities, without joint ownership among them. These agreements on cash holding collaboration are based on non-formal contracts. 
This collaboration among companies regarding cash actions is only possible under certain circumstances; the key is the determination of those circumstances. Efficiency in managing cash, or part of it, could be replaced by collaboration between companies, thus at least reducing dependency on banking intermediation, allowing these companies to have their own sustainable financing system with "a policy of caring for future generations" (Soppe 2004, p. 221). A holistic approach is considered in which all the portfolio of stakeholders and their interests are included. Banks are only one of the stakeholders, and are not the core or a unique element in the financial area (Soppe 2004; Fatemi and Fooladi 2013) However, there are some limitations: this model cannot be used to manage all the cash amount, only to collaboratively manage part of the cash.

This model is a quantification of some real initiatives that we have used in real companies in the exploratory analysis, rather than just for theoretical analysis, including: Mondragon Corporation, Arboribus, and Trocobuy ((Beraza et al. 2016) provided an in-depth exploratory analysis of the influence of size and sector on the model). The companies, as a group with aligned interests and needs, are able to manage their cash, at least in part, more efficiently. Then, the case studies prove that some specific conditions are needed to develop those types of collaborative models: a different form to understand and manage the company, trust-based management, and common-interest-based management. Our model could be cataloged as a new and sustainable management system.

There is a common understanding of how the management of a company is optimized: attaining company efficiency based on their own results without considering the option of collaboration, and the sustainability based on the portfolio of stakeholders is not even analyzed or considered (Soppe 2004). If cash deficits occur and the company is not fit to be a borrower, then the company must assume and support external banking restrictions. The results of this situation could penalize the company, worsen their financial problems, and perhaps lead to the bankruptcy and disappearance of companies, harming future generations. However, there is an option to collaborate ((San-Jose 2009) provided for a theoretical proposal) in which companies pool their cash, surpluses, or deficits depending on their current situations that could enable the overcoming of banking restrictions. Along these lines, but based on cash flow and focused on the supply chain, there is evidence (a model and a case) showing that it is possible to share the cash flow created by partners in a supply chain (Comelli et al. 2009). We seek to contribute to this evidence but without restricting the model to the supply chain, basing the model on cash holding rather than the narrower concept of cash flow.

\subsection{Hypotheses Development}

Based on the literature ((Soppe 2004; Madhok and Tallman 1998; Hogan 2001); among others) and on cases already analyzed (Mondragon Corporation, Trocobuy, and Arboribus), we established six hypotheses:

Hypotheses 1. Transparency positively influences trust between companies in collaborative and sustainable cash management relationships.

Academics in the area of business economics have investigated transparency in various contexts: ethical management and decision-making in companies, relational transparency in inter-relationships (Eggert and Helm 2003; Gounaris 2005), organizational transparency from the stakeholder perspective (Rawlins 2008), supply relationships (Lamming et al. 2004), development of organizational trust (Pirson and Malhotra 2011), and the financial markets and corporate disclosure (Bushman et al. 2004; Schnackenberg and Tomlinson 2016). Thus, there is no consensus on the theoretical foundation, which is multidisciplinary and context-specific in nature. This construct has led to a wide variety of forms of measurement without producing any consensus from academia, so creating a unique measurement scale to be comprehensively applied by researchers has not been possible (Schnackenberg and Tomlinson 2016). However, transparency is assumed to include at least three aspects: disclosure, clarity, and accuracy (Schnackenberg and Tomlinson 2016), which are included in our one-dimensional transparency construct. Although trust can exist without transparency, it seems logical to assume that 
transparency can generate trust, as transparency means that any participant can verify information, processes, and decisions. Regardless of whether a participant actually does so, the fact that they are able to is reassuring, and the very existence of transparency provides a method of checking for potential fraudulent behavior. Thus, transparency may be considered an element that is conducive to trust, so that a positive causal relationship exists between them: the greater the transparency, the greater the trust.

Hypotheses 2. Expectations positively influence trust between firms in collaborative and sustainable cash management relationships.

Trust seems to require the existence of positive expectations regarding the outcome of the system both in terms of the potential value generated and the working of the model itself. Without such expectations, it seems unlikely that the basic trust required to enable the system to work could exist; by contrast, it seems logical to assume that the more positive the expectations, the greater the confidence should be among participants as a whole. For example, expectations are considered a one-dimensional construct from a value perspective, which combine aspects of the theory of transaction costs and resource-based theory, taking the context of collaborative relationships between companies as its unit of analysis (Blakstad and Allen 2018).

Hypotheses 3. Guarantees positively influence trust in collaborative and sustainable cash management relationships.

Motivated by prudence as a reason for holding cash surpluses, in this model, we included guarantees as an important construct, which include not only real guarantees but also the minimum cash level held by the group, regulations and a mechanism to reduce risks, and potential opportunistic behavior (Chang 2000; Locorotondo et al. 2014). In any financial system, risks and benefits are intertwined: once positive expectations of benefits have been established, trust can be expected to increase if risks decrease simultaneously. One way of reducing risks (though not the only one- transparency would be another) is to offer guarantees so that if risks materialize their effects can be offset. Thus, the more guarantees there are (converging with risk reductions) the more trust will increase. When organizations interact along time and the relationship progresses positively, strong expectations of trust appear, and opportunistic behavior is reduced, therefore guaranteeing loses importance over time (Inkpen and Currall 1988). However, the guarantees are considered as a good complement to confidence.

Hypotheses 4. Trust between companies positively influences the management of collaborative and sustainable cash management relationships.

Trust, as we noted above, is relevant in a sharing economy context; trust needs to be generated by individuals as it can reduce the negative impact of the risks assumed. Some empirical evidence supports the idea that trust has positive effects on online financial exchanges, reducing the perceived risk (Pavlou 2003; Pavlou and Gefen 2004) and facilitating the completion of transactions (McKnight et al. 2002; Gefen and Straub 2004) Trust is considered, in general, as a complex multidimensional construct from a theoretical viewpoint (Seppänen et al. 2007; Whipple et al. 2013); however, from the analysis viewpoint, trust is treated empirically in most studies as a one-dimensional construct (Morgan and Hunt 1994). In general, trust is a mixture of dimensions or a single dimension, but it considers ability, benevolence, and integrity. For example, in the organizational literature, McEvily and Tortoriello (2011) listed a total of 38 different dimensions of trust over 46 identified multidimensional measures, considering the following as particularly significant: competency, ability, benevolence, integrity, and credibility. Our trust construct is based on this one-dimensional view but we shifted some aspects to the financial area. We focused on reductionism rather than universalism. Trust is fundamental for the proper management of a sustainable system because the system requires power and responsibility to be delegated and this is unlikely to happen without trust. We assumed that the greater the trust, the less restrictive the management system, and the lower the transaction costs 
linked to monitoring risk. Accordingly, the existence of a positive causal relationship between increased trust among participants and improvements in process management appears logical, especially when that trust is linked to a high level of transparency.

Hypotheses 5. Management positively influences guarantees between companies in collaborative and sustainable cash management relationships.

The potential success of an organization in attaining its economic and social objectives therefore depends on how managers fulfill their responsibilities in order to achieve those objectives. Management is measured to show the efficiency of a manager in performing differently based on collaboration and sustainable principles (Preston and O'bannon 1997). Any system guarantees require adequate management, so a better management system will, all else being equal, result in a better system of guarantees, especially when management efficiency itself tends to be one of the main ex-ante guarantees. Thus, it seems logical to expect improvements in management to improve the guarantees of the system, and therefore increase the trust in the system.

Hypotheses 6. Management positively influences mutual benefits between firms in collaborative and sustainable cash management relationships.

Linked to expectations (ex-ante), the mutual benefit dimension (ex-post) is based on economic, social, and emotional indicators. In this regard, the benefit construct could be developed by including financial and accounting performance indicators such as profitability, net income, financial performance, and market return (Kalmi 2017). However, social indicators could also be included (San-Jose and Retolaza 2016). From the resource-based perspective, some authors (Madhok and Tallman 1998) defined value considering the value created through collaboration on the income obtained only because of this particular alliance. In this paper, mutual benefit is measured based on this point of view, in which value is created due to collaboration between companies and is not exclusively limited to financial value. The mutual benefit expected from this system depends both on its potential (in relation to the expectations generated) and its proper working (management). Under these assumptions, good management should have a positive influence on this outcome, i.e., the better the system is managed, the better the outcome, which means that there is a positive causal relationship between the two variables.

Then, our challenge was to establish the factors that could permit a cash-related collaboration and a sustainable economy between companies. If possible, at least theoretically, a new cash-system among companies could be created. Then, a new strategy could be developed in line with $\mathrm{Li}$ et al. (2016). The findings suggest that there are six factors necessary to develop a collaborative cash holding model among companies: expectations, transparency, trust, management, guarantees, and benefits. These are all parts of the same reality and suggest that the collaborative economy could be widespread in relationships between companies, and that some major points, such as guarantees, benefits, and trust, are essential to maintaining long-term collaboration between companies, for establishing policies of caring for future generations, and considering all stakeholders.

\subsection{Framework}

The paper is organized as follows. Section 2 describes our model and the sample and explains the research method used to test our hypotheses. Section 3 discusses the results of the study. The paper ends with conclusions and some remarks on the limitations of the research. 


\section{Model, Materials, and Methods}

\subsection{Model}

All the relationships explained in the previous section are part of our theoretical model, which is not only based on the cases but also on the previous theories relating the constructs, collaboration, and sustainable systems (Soppe 2004; Madhok and Tallman 1998; Hogan 2001; Li et al. 2016).

The model is shown in Figure 1, including the six dimensions of the model and the relationships expected between the constructs.

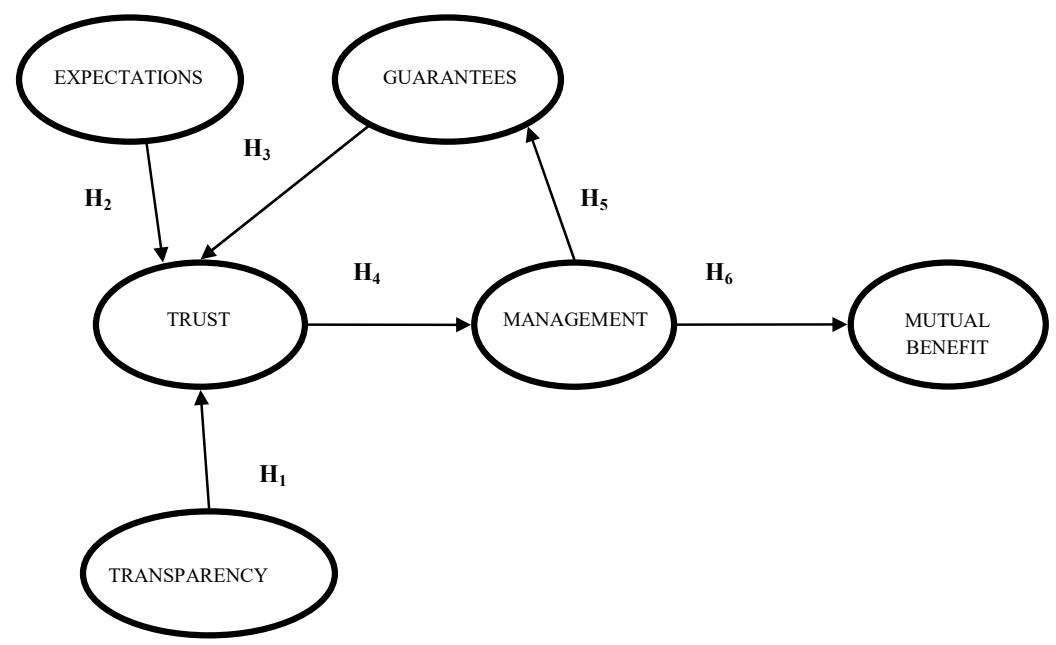

Figure 1. Collaborative and sustainable model for cash holding.

The model is composed of one-dimensional and first-order constructs. All of them can be measured by formative indicators, not only including exogenous constructs such as expectations, guarantees, and transparency, but also to endogenous factors such as trust, management, and mutual benefit. Based on Söllner and Leimeister (2010) and as argued in our hypotheses (from H1 to H6), trust comes from other previous constructs in the shape of expectations, transparency, and guarantees, but trust also positively influences management and mutual benefit. To summarize, the model integrates the short-term (e.g., management/guarantees) and long-term (feedback between expectations and mutual benefits) relationships between constructs that enable the overall model to be attained.

\subsection{Sample}

For this study, 3126 top financial officers in Spain were surveyed during 2015. The participants were treasurers or chief financial officers (CFOs) of companies belonging to Spanish Association of Financial Officers and Treasurers. Of the respondents, 38\% were CFOs, 29.69\% were treasury managers, $16.91 \%$ were managers or administrators, and $15.04 \%$ were accounting managers. The professional profile of the financial experts is relevant, so we included this constraint: following Custódio and Metzger (2014), we based our results on the idea that firms with financial experts hold less cash and more debt, and are more financially sophisticated, so the implications and potential financial innovations increase with this constraint in the sample.

The model that we propose here is based on a few cases. The generalization in the identification of the causal relationship between the possible elicited variables can only be addressed from the intentions of the managers. Therefore, a questionnaire-based method for this purpose was adequate. It was necessary to introduce a limitation: with this method, we do not analyze the intentions of using cash-sharing in a company, but this was not the aim of our research. Our investigation focuses on financial practices by those in a company whose responsibility is attributed to the CFO; therefore, we considered the members of the Spanish Association of Financial Officers and Treasurers as being high quality representatives of the sector in Spain. However, this selection may involve two biases: 
the orientation toward large companies that have a proportionally greater weight in the Spanish Association of Financial Officers and Treasurers and a greater interest in knowledge and financial innovations. We emphasize here that with this work we attempt to contrast the variables or factors that should be included in a new cash-sharing model, which is possibly more suitable for medium-large companies. However, none of the mentioned biases should have significantly impacted the result (Custódio and Metzger 2014). Our response would be different if asked about the actual availability of the model, where the result could have been more positive than in the general population, in which small companies would be considered.

Based on the calculation of random sampling and starting from an estimated population of 27,889 large- and medium-sized companies in Spain, and with a maximum sample error of 4.5 and a probability error of $50 \%$, we received 412 valid responses to the questionnaires (three questionnaires were invalidated, thus leaving the sample in 409 companies and with a margin of error of 4.52). For the selection of the sample, a systematic probabilistic sampling was used based on a table of random numbers generated with Microsoft Excel, with lower limit 1 and upper limit of 3.126. In the cases in which the appropriate subject did not answer the questionnaire, after several attempts, the next higher number was selected. The process was completed upon reaching the 412 answered questionnaires.

\subsection{Measurement and Reliability of Variables}

All items were self-scored using five-point Likert scales. We followed the recommendations by MacKenzie et al. (2011), and Bollen and Lennox (1991) for the conceptualization of the constructs. The questionnaire items were based on the theory that we will explain next, and on three companies (Mondragon Corporation, Trocobuy, and Arboribus) that collaboratively manage their cash. Pre-validation of the questionnaire was completed with a group of financial experts to measure the questionnaire validity. Then, expectations construct was measured using the argument of Madhok and Tallman (1998) and Hogan (2001). Trust was measured using a scale based on the items developed by Seppänen et al. (2007) and McEvily and Tortoriello (2011), but the cash management collaboration viewpoint is included. Transparency was based on the items developed by (Schnackenberg and Tomlinson 2016), including the aspects of disclosure, clarity, and accuracy and including transparency in relationships (Eggert and Helm 2003). The guarantees construct included aspects related to cash management, i.e., real guarantees, but also those relevant for guaranteeing the management of cash between companies, such as minimum liquidity, balanced distribution of risk, and establishing the sharing of part of their cash (Chang 2000; Locorotondo et al. 2014). Mutual benefit was based on Madhok and Tallman (1998).

\subsection{Methodological Process for Creating the Questionnaire: Internal and External Validity}

The survey was created to ensure the validity of the contents. Specifically, it was designed to elicit information on the relevance of the six variables proposed and the links between them to confirm the suitability and consistency of the proposed model. The variables studied were detected in the preliminary phase of research based on an analysis of three actual case studies of collaborative treasury management (Mondragon Corporation, Trocobuy, and Crowdfunding-Arboribus), as explained by (San-Jose and Retolaza 2016). The model was then created, and its suitability and consistency were checked via in-depth personal interviews with financial management staff from several firms to ensure that the model was also applicable to other businesses and organizations: Idom, LantegiBatuak, Arteche, Borges Mediterranean Group y Bahia de Bizkaia Gas (Spanish medium-sized companies that are technologically innovative with sustainability goal). A total of 36 items were thus identified. The interviews were semi-structured and lasted around 40 minutes each. They were recorded and transcribed in half the cases. A pilot survey was then designed with the 36 items identified, which respondents were asked to answer by applying a five point Likert scale (see Beraza et al. 2016 for a descriptive analysis). 
The external validity of the pilot survey was then tested to determine whether the 36 items identified served to explain, create, or construct the six constructs detected. The pilot survey was emailed to a group of experts along with a letter introducing the study. Replies were received from 23 experts in September 2014. In five cases, $20 \mathrm{~min}$ interviews were held to review the survey and obtain a better understanding any potential doubts and problems contained therein. Considerable emphasis was placed on this part of the work because the survey had been sent out online and there was no opportunity for feedback between interviewers and interviewees in the rest of the cases. The average score for each item was determined and the survey was then revised on the basis of the following criteria: (1) items with a weighting of less than three were eliminated as they were not important in explaining the concept; (2) items weighted at four or less were revised; and (3) items waited at more than four were reviewed and revised only if deemed appropriate. Changes were made in the wording of 28 of the items, and some financial terminology was changed to clarify the meaning of each item. One item was deleted and a new item was incorporated on the basis of observations and remarks by the experts. Finally, with the support of the experts, we determined that the items used were valid for explaining the six constructs (expectations, trust, transparency, guarantees, management and mutual benefit). At this external validation stage, the experts were expected to review the constructs and not the model itself, i.e., to check whether the items explained the full significance of each construct. This was confirmed: these items can be taken as possible causes for each construct.

Following its review and subsequent validation, the final survey contained 36 items (Table A1) in six blocks, one for each construct: expectations, trust, transparency, guarantees, management and mutual benefit. Some general questions were included (sector of activity, number of employees in the company, date founded, respondent sex and title at the company) for purposes of profiling of respondents and the companies where they work, and so that these variables could be used as determining factors in behavior and predisposition to deploy collaborative and sustainable model for cash holding at their respective companies.

\section{Results}

We reviewed the Pearson correlation matrix, which showed the relationship between the items for each construct and between items from different constructs. The matrix suggests that the constructs are part of the same reality; a single model was sought to provide an overall explanation. The analysis of correlations and means showed that the financial experts participating in our study appear to understand that trust and management, for developing this cash-based collaborative model, are more important than other factors. Both the empirical evidence and theoretical literature support the hypothesis that collaborative management requires other methods of managing financial aspects and is probably more able to undertake financial innovation and the creation sophisticated tools. Trust and guarantees are necessary factors that create the possibility of collaborative cash management. There is also a need to reduce risk and opportunistic behavior (Hamari et al. 2016; Soppe 2004; Comelli et al. 2009).

\subsection{Analytical Techniques}

We analyzed data using the maximum likelihood structural equation modeling technique based on Partial Least Squares (PLS) with the program Smart PLS 3 Professional (Ringle et al. 2016). PLS is based on principal components analysis and orthogonal rotation, which is acceptable for determining the measurement model. Other programs, such as linear structural relations called LISREL (it is a proprietary statistical software package used in structural equation modeling), could produce similar results, despite the limited sample size. PLS application consists of a confirmatory model of structural equations that enable a model to be constructed with a system of one-way effects between two variables on a path diagram. That diagram represents the relationships between dependent and independent variables and the correlations between constructs and indicators. The objective of PLS is to provide certain values for latent variables so that predictions can be made. The model specifically defines latent variables as linear combinations of its observed measures, and the relationships between latent variables 
are assumed to not be interdependent. The PLS technique seeks to explain the variance in all the variables involved - both latent and observed-which results in an attempt to maximize the variance explained $\left(R^{2}\right)$ in the latent variables. We selected the PLS model because all the constructs that create the structural model are measured by means of formative indicators; with six constructs, 36 indicators and 321 observations, the numbers involved are not excessively high. As the original populations from which the data were extracted do not comply with the assumptions of normality and homoscedasticity, PLS provides flexible model in line with the conditions present in social and behavioral science, so is a suitable alternative for creating structural models in the specific field of business.

Many studies (Söllner and Leimeister 2010; Bollen and Lennox 1991), showed that there may be potentially serious consequences if the measurement model is incorrectly specified. Inaccurate conclusions or different conclusions concerning the structural relationships between constructs may be reached.

The constructs in the model are measured by formative indicators (Bollen and Lennox 1991) which are observed variables that act in a causal, predictive, or preceding fashion in regards the construct. In the case considered here, all the constructs are one-dimensional, i.e., first-order and formative. The same applies to the constructs that occupy exogenous positions (expectations, guarantees, and transparency) and those that occupy endogenous positions (trust, management and mutual benefit). Thus, causality flows from the ex-ante constructs (expectations, transparency, and guarantees) toward trust, and finally from management toward mutual benefit. Notably, the methods traditionally used to determine the reliability and validity of reflective measurement models are not suitable for use with constructs where the direction of causality is precisely the opposite (Bollen and Lennox 1991). For this reason, Diamantopoulos and Diamantopoulos and Winklhofer (2001) suggested specific procedures for measuring and assessing formative constructs. Instead, content validity should be assessed before empirically evaluating the formative measurement model to ensure that formative indicators capture all or the main facets of the construct. We applied a content specification in which the domain of the content that the indicators try to measure has been clearly specified. We provided a set of indicators that exhaustively cover the domain of each formative construct. To reinforce the justification of the operationalization of the construct as formative, we reviewed the literature and ensured a reasonable theoretical foundation, as was developed in Section 2. In short, the validity must be tested based on theoretical reasoning and the opinion of experts Diamantopoulos and Winklhofer (2001). In practice, formative models are not easy to defend because the researcher must be completely sure that all the possible causes of the latent variable have been considered by the indicators Diamantopoulos and Winklhofer (2001). For that reason, it is absolutely essential that research includes formative measures and the PLS technique must be used to establish an acceptable level of validity of measurement before continuing with the structural analysis of relationships. Below, the measurement model is first assessed through a multicollinearity analysis in the formative measurement model, and second, by the assessment of the significance and relevance of the formative indicators. The structural model was then used to test for the hypothesized relationships.

\subsection{Formative Measurement Model Evaluation}

The measurement properties of the scales used in this study were examined through the estimation of a measurement model. The evaluation of the formative measurement model was completed in the following two steps: (1) multicollinearity analysis and (2) assessment of the significance and relevance of the formative indicators.

\subsubsection{Multicollinearity Analysis}

High correlations between items in formative measurement models, also referred to as collinearity, are not expected. When more than two indicators are involved, this situation is called multicollinearity. We analyzed the variance inflation factor (VIF) to determine whether multicollinearity between items can be rejected. Table 2 shows the results of the multicollinearity analysis. 
Table 2. Results of the multicollinearity analysis.

\begin{tabular}{|c|c|c|}
\hline Construct and Scale item & Stan. Loading & Collinearity Statistics VIF \\
\hline \multicolumn{3}{|l|}{ Expectations (E) } \\
\hline 1 SYNERGIES & 0.663 & 1.245 \\
\hline 2 CYCLESCOM & 0.710 & 1.391 \\
\hline 3 DATACOM & 0.679 & 1.363 \\
\hline 4 SAVE & 0.687 & 1.310 \\
\hline 5 NETCOST & 0.616 & 1.257 \\
\hline \multicolumn{3}{|l|}{ Trust (TRU) } \\
\hline 7 MANAGSIST & 0.778 & 1.821 \\
\hline 8 POSITVALUE & 0.696 & 1.497 \\
\hline 9 REJECTOPORT & 0.733 & 1.574 \\
\hline 10 PREDISPOSITION & 0.814 & 1.914 \\
\hline 11 POSTPONE & 0.461 & 1.135 \\
\hline 12 SKILLSMNG & 0.781 & 1.885 \\
\hline \multicolumn{3}{|l|}{ Transparency (TRA) } \\
\hline 13 FULLINFO & 0.633 & 1.293 \\
\hline 14 ACCURATEINFO & 0.771 & 1.709 \\
\hline 15 IRISK & 0.698 & 1.511 \\
\hline 16 GRIMEM & 0.534 & 1.231 \\
\hline 17 PANEL & 0.750 & 1.635 \\
\hline 18 CASHPLAN & 0.736 & 1.588 \\
\hline \multicolumn{3}{|l|}{ Guarantees (G) } \\
\hline 19 LIQUIDITY & 0.609 & 1.213 \\
\hline 20 REAL & 0.658 & 1.359 \\
\hline 22 NOOPPORT & 0.752 & 1.490 \\
\hline 23 NORMATIVE & 0.739 & 1.464 \\
\hline 24 RISKSIM & 0.494 & 1.224 \\
\hline \multicolumn{3}{|l|}{ Management (MA) } \\
\hline 25 EFFICIENCY & 0.773 & 1.693 \\
\hline 26 BENEFCOST & 0.658 & 1.384 \\
\hline 27 COSTCOMP & 0.609 & 1.323 \\
\hline 28 INFOSIM & 0.681 & 1.421 \\
\hline 29 CONTROL & 0.752 & 1.919 \\
\hline 30 CONTINGPLAN & 0.782 & 1.960 \\
\hline \multicolumn{3}{|l|}{ Mutual Benefit (MB) } \\
\hline 31 NOECONBENE & 0.502 & 1.120 \\
\hline 32 TOTALBENEFIT & 0.592 & 1.202 \\
\hline 33 BEENFITINDEX & 0.728 & 1.405 \\
\hline 34 PREVFUTURBEN & 0.693 & 1.357 \\
\hline 35 VERIFYBEN & 0.595 & 1.207 \\
\hline 36 SYMMETRYBEN & 0.592 & 1.180 \\
\hline
\end{tabular}

Note: the acronyms of items 1 to 36 are explained in Appendix A. In social science, weaker loading is often observed, especially when recently developed measurement scales are applied. For that reason, when the loading is between 0.4 and 0.7 before eliminating it, it is advisable to analyze what impact its elimination could have on composite reliability and average variance extracted (AVE). If its elimination entails an increase in the threshold value of these measurements suggested above $(\mathrm{AVE}=0.5$; Composite Reliability $=0.7)$ the item can then be eliminated, and otherwise it can be retained. Indicators with loadings below 0.4 should be eliminated from the scale. This has led to the COMBENEFIT indicator being eliminated in the "expectations" construct. 
According to the results in Table 2, CONTROL has the highest VIF value (1.919). All VIF values are uniformly below the threshold value of five Diamantopoulos and Winklhofer (2001); (Hair et al. 2011) so the collinearity does not reach critical levels in any of the formative constructs. We concluded that there is no risk in applying the path analysis.

\subsubsection{Assessment of the Significance and Relevance of the Formative Indicators}

To assess the measurement model, we analyzed the significance and relative and absolute importance (weighting and loading) of the indicators. This analysis was conducted by calculating the PLS algorithm specifically by bootstrapping (5000 sub-samples; 321 cases, "no changes in sign", significance level 0.05, and two-tailed test). As shown in Figure 2, the weights of the indicators do not in general exceed the maximum of $0.408(1 /(\sqrt{ }$ No. indicators $)=1 /(\sqrt{ } 6))$. We decided to eliminate the item CASHPER for both empirical and conceptual reasons. From an empirical viewpoint, this item has a non-significant negative weight $(-0.032 ; \rho$-value $=0.650)$ in the sample used here, so we decided to follow the recommendation of Cenfetelli and Bassellier Diamantopoulos and Winklhofer (2001) and eliminate it.

The evaluation of the measurement model ended with the analysis of the relative and absolute contribution of the indicators to their respective constructs, based on the results obtained, we considered that all constructs measured formatively have satisfactory quality levels.

\subsection{Structural Model and Testing of Hypotheses}

Once the measurement model was satisfactorily evaluated, the next step was to assess the structural model constructed from the relationships hypothetically established between the constructs based on the initial theoretical model. In the context of PLS, the structural model must be designed as a causal chain. Such models are known as "recursive models", i.e., there can be no cyclical relationships in the structural model. Hence, the PLS could not be used to analyze our model as a whole, so we decided to analyze H5 separately (Figure 2). Our model was analyzed by aggregating the items that reflect a one-dimensional construct. The results are provided in Table 3.

Table 3. Path analysis results.

\begin{tabular}{|c|c|c|c|}
\hline Hypothesis & Path Coefficients $\beta$ & $\rho$-Value (Bootstrap) & Hypothesis Confirmed \\
\hline $\begin{array}{l}\text { H1: Transparency positively influences } \\
\text { trust between companies in collaborative } \\
\text { cash management relationships. }\end{array}$ & 0.238 & 0.000 & YES \\
\hline $\begin{array}{l}\text { H2: Expectations positively influence trust } \\
\text { between firms in collaborative cash } \\
\text { management relationships. }\end{array}$ & 0.264 & 0.000 & YES \\
\hline $\begin{array}{l}\text { H3: Guarantees positively influence trust in } \\
\text { collaborative cash management } \\
\text { relationships. }\end{array}$ & 0.414 & 0.000 & YES \\
\hline $\begin{array}{l}\text { H4: Trust between companies positively } \\
\text { influences the management of collaborative } \\
\text { cash management relationships. }\end{array}$ & 0.623 & 0.000 & YES \\
\hline $\begin{array}{l}\text { H5: Management positively influences } \\
\text { guarantees between companies in } \\
\text { collaborative cash management } \\
\text { relationships. }\end{array}$ & $\begin{array}{l}\text { Not estimated } \\
\text { directly }\end{array}$ & $\begin{array}{l}\text { Not estimated } \\
\text { directly }\end{array}$ & Not estimated directly \\
\hline $\begin{array}{l}\text { H6: Management positively influences the } \\
\text { mutual benefit between firms in } \\
\text { collaborative cash management } \\
\text { relationships. }\end{array}$ & 0.668 & 0.000 & YES \\
\hline
\end{tabular}

The standardized path coefficients can be said to be significant as their minimum value was 0.2 ( $\mathrm{H} 1$ and $\mathrm{H} 2)$, but, in most cases, they were ideal, as their values were greater than $0.3(\mathrm{H} 3, \mathrm{H} 4$, and $\mathrm{H} 6)$. 
The stability of the estimates provided by PLS was examined using the non-parametric technique known as bootstrapping (Table 4). This process can be used to determine whether a formative indicator contributes significantly to the corresponding construct, as well as to determine the significance of the path coefficients by calculating the standard error, Student's t-value, $\rho$-value, and the confidence intervals.

Table 4. Contribution of the predictive variable to the variance explained.

\begin{tabular}{ccccc}
\hline $\begin{array}{c}\text { Relationships Proposed in } \\
\text { the Structural Model }\end{array}$ & $\begin{array}{c}\text { Path Coefficient } \\
\boldsymbol{\beta}\end{array}$ & Correlation & $\begin{array}{c}\text { Variance } \\
\text { Explained }\end{array}$ & $\begin{array}{c}\text { \% of Variance } \\
\text { Explained }\end{array}$ \\
\hline Guarantees-Trust & 0.414 & 0.659 & 0.273 & 27.3 \\
Expectations-Trust & 0.264 & 0.544 & 0.143 & 14.3 \\
Transparency-Trust & 0.238 & 0.527 & 0.129 & 12.9 \\
Trust-Management & 0.623 & 0.623 & 0.388 & 38.8 \\
Management-Mutual Benefit & 0.668 & 0.668 & 0.446 & 44.6 \\
\hline
\end{tabular}

It was necessary to check the significance of all the relationships established in our structural model. When results were interpreted each estimator was analyzed, though there was no need to include them all in the report on the results, since they all lead to the same conclusion. The path coefficients and, by extension, the hypotheses accepted are those that are significant: in the model, which include the five tested hypotheses ( $\mathrm{H} 1, \mathrm{H} 2, \mathrm{H} 3, \mathrm{H} 4$, and H6). However, the goal of PLS is to identify not just which path coefficients are significant but also which of the significant relationships are most significant.

Finally, if there are mediating constructs, then their direct and indirect effects must be analyzed, which is calculated as the product of the coefficient paths along the causal line between two indirectly related variables (Douglas and Craig 2009). The public perception of shared goods has changed substantially in the past few years. While co-owning properties has been widely accepted for a while (e.g., timeshares), the notion of sharing bikes, cars, or even rides on an on-demand basis is just now starting to gain widespread popularity. The emerging "sharing economy" is particularly interesting in the context of cities that struggle with population growth and increasing density. While sharing vehicles promises to reduce inner-city traffic, congestion, and pollution problems, the associated business models are not without problems themselves. Using agency theory, in this article we discuss existing shared mobility business models in an effort to unveil the optimal relationship between service providers (agents) and the local governments (principals) to achieve the common objective of sustainable mobility. Our findings show private or public models are fraught with conflicts, and point to a merit model as the most promising alignment of the strengths of agents and principals (Douglas and Craig 2009).

To determine the contribution of predictive variables to the $R^{2}$ (variance explained) of the endogenous variables in the model proposed, it was necessary to calculate the absolute value of the result of multiplying the path coefficient by the correlation between each pair of constructs (Hair et al. 2011). The result is interpreted as the variance of the endogenous construct explained by the predictive variable. We considered that the predictive variable should be able to explain at least $1.5 \%$ of the endogenous variable.

In our case, all the predictive variables explained more than $1.5 \%$ of the endogenous variable. These results confirm the conclusions reached in analyzing the path or standardized regression coefficients between the constructs.

The next step was to determine the accuracy and stability of the parameter estimates so that our hypotheses could be tested. We completed this using bootstrapping (5000 sub-samples, 321 cases, "no change in sign" as the algorithm option, significance level 0.05, and two-tailed testing), which produced the standard error, Student's t-value, the $\rho$-value, and the confidence intervals. Table 5 shows that all the path coefficients are significant $(\rho$-value $<0.05)$ for an error probability of $5 \%$. 
Table 5. Significance of path coefficients.

\begin{tabular}{ccc}
\hline Construct Relationship Coefficients & $\boldsymbol{\beta}$ & $\boldsymbol{\rho}$-Value \\
\hline Guarantee $\rightarrow$ Trust & 0.414 & 0.000 \\
Expectations $\rightarrow$ Trust & 0.264 & 0.000 \\
Transparency $\rightarrow$ Trust & 0.238 & 0.000 \\
Trust $\rightarrow$ Management & 0.623 & 0.000 \\
Management $\rightarrow$ Mutual Benefit & 0.668 & 0.000 \\
\hline
\end{tabular}

Table 6 shows the total effect of each variable on the rest and the corresponding $\rho$-values. They are all significant.

Table 6. Significance of the total effects of the variables.

\begin{tabular}{ccc}
\hline Construct Relationships & Total Effect & $\rho$-Value \\
\hline Trust $\rightarrow$ Mutual Benefit & 0.416 & 0.000 \\
Trust $\rightarrow$ Management & 0.623 & 0.000 \\
Expectations $\rightarrow$ Mutual Benefit & 0.110 & 0.000 \\
Expectations $\rightarrow$ Trust & 0.264 & 0.000 \\
Expectations $\rightarrow$ Management & 0.164 & 0.000 \\
Guarantees $\rightarrow$ Mutual Benefit & 0.172 & 0.000 \\
Guarantees $\rightarrow$ Trust & 0.414 & 0.000 \\
Guarantees $\rightarrow$ Management & 0.258 & 0.000 \\
Management $\rightarrow$ Mutual Benefit & 0.668 & 0.000 \\
Transparency $\rightarrow$ Mutual Benefit & 0.099 & 0.000 \\
Transparency $\rightarrow$ Trust & 0.238 & 0.000 \\
Transparency $\rightarrow$ Management & 0.148 & 0.000 \\
\hline
\end{tabular}

Given these last results, the total effect of each variable on the rest is significant $(\rho$-value $<0.05)$, at least at the $5 \%$ level. As we had to adapt the model, eliminating the path between management and guarantees to prevent a cyclical relationship between trust-management-guarantees-trust and thus meet the requirements for PLS estimation, we cannot confirm within the structural model whether the relationship between management and guarantees is significant, or determine the sign of that relationship. However, we checked for a bivariate correlation between these two variables by estimating Spearman's Rho coefficient using the IBM SPSS Statistics 22 software program.

Table 7 shows that the guarantees and management constructs are significantly correlated (Spearman's Rho coefficient $=0.567$ at the 0.01 level), which does not imply that there is causality between them, but simply that they are linearly related. This relationship is shown in Figure 2 with a dotted line.

Table 7. Correlations between guarantees and management.

\begin{tabular}{|c|c|c|c|c|}
\hline & & & Guarantees & Management \\
\hline \multirow{6}{*}{ Spearman's Rho } & \multirow{3}{*}{ Guarantees } & Correlation coefficient & 1.000 & $0.567 *$ \\
\hline & & Significant level & & 0.000 \\
\hline & & $N$ & 323 & 323 \\
\hline & \multirow{3}{*}{ Management } & Correlation coefficient & $0.567^{*}$ & 1.000 \\
\hline & & Significant level. & 0.000 & \\
\hline & & $N$ & 323 & 323 \\
\hline
\end{tabular}

* Significant at 0.01 level.

The predictive power of the model was measured via the $R^{2}$ (variance explained) for the dependent latent variables. Hair et al. (2011) considered a figure of 0.1 or more as a suitable value for 
variance explained. Lower figures indicate that the dependent latent variable in question has a lower predictive power.

As shown in Table 8, the predictive power of the model is adequate, since all the endogenous constructs have $R^{2}$ values in excess of 0.1. Specifically, following the criteria in Hair et al. (2011) and Douglas and Craig (2009), the predictive power of the constructs is moderate in the case of trust (0.542) and close to moderate for management (0.388) and mutual benefit (0.447). In these last two cases, the $R^{2}$ are close to 0.5 or even higher, which is the level classified as moderate.

Table 8. Predictive power of the model.

\begin{tabular}{ccc}
\hline Endogenous Variable & $\boldsymbol{R}^{\mathbf{2}}$ & Predictive Power \\
\hline Trust & 0.542 & Moderate \\
Management & 0.388 & Close to moderate \\
Mutual Benefit & 0.447 & Close to moderate \\
\hline
\end{tabular}

Table 9 provides our analyses of the relative explanatory power or size effect $\left(f^{2}\right)$ of the model. The change in $R^{2}$ shows whether an independent variable has any substantial influence on the dependent latent variable. Following the criteria in Cohen and Kietzmann (2014) the size effect is considered to be approximately average in the case of the three constructs that influence trust, but large on trust itself and very large on management.

Table 9. Relative explanatory power (size effect).

\begin{tabular}{ccc}
\hline Variable & $f^{2}$ & Size Effect \\
\hline Expectations $\rightarrow$ Trust & 0.115 & Average \\
Transparency $\rightarrow$ Trust & 0.093 & Small to average \\
Guarantees $\rightarrow$ Trust & 0.241 & Average to great \\
Trust $\rightarrow$ Management & 0.633 & Great \\
Management $\rightarrow$ Mutual Benefit & 0.807 & Very great \\
\hline
\end{tabular}

It is not possible to analyze predictive relevance by estimating the parameter $Q^{2}$ and its corresponding size effect $q^{2}$ because they cannot be estimated for endogenous constructs measured formatively.

The model was confirmed not only theoretically in terms of the theoretical relationships explained by each construct in itself, but also through a structural model of equations that permitted confirmation through statistics. As shown in Figure 2, on the basis of the data obtained from the PLS, trust, management, and mutual benefit are the most important variables in this sustainable financial model. Thus, as occurs in the collaborative economy, this model shows that trust is the key factor, covering reputation assessment systems and traditional mechanisms, as a preliminary and/or supplementary step in the need for regulation. Mutual benefit arises from the social, financial, and environmental value created on the basis of the values that drive the collaborative economy, i.e., the feeling of belonging to a community and interactions between the parties involved, which are extended through the network effect. 


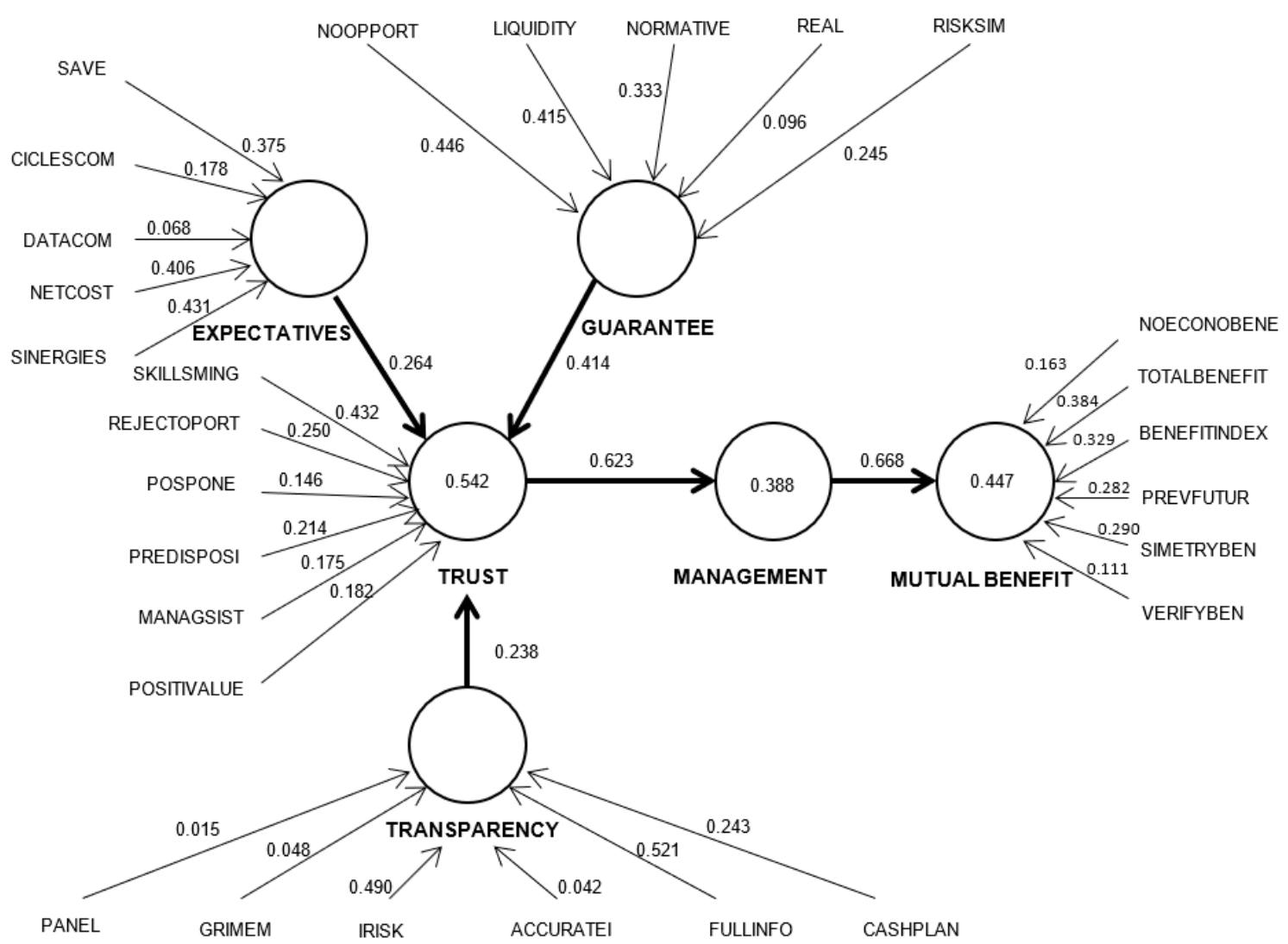

Figure 2. A collaborative and sustainable model for cash holding: structural model.

\section{Discussion}

The first contribution of our paper is the notion that the model calls into question, or at least may significantly reduce, the need for banks as intermediaries in treasury management, along the lines of the FinTech model. This is not proven here, but it is an option to consider. Then, it is possible that this model is just one element in the system that concerns treasury management. This model can considerably reduce the need for cash from outside the system itself, but the model seems to require a capacity and guarantees in management, which banks may be more qualified to provide. This would entail banks transitioning from funding providers to service providers, which seems to be in line with the digital transformation that they are trying to undertake. Then, we suggest that if conventional banks are not including this type of system in their own services, other companies would have the opportunity to specialize in this type of collaborative intermediation.

Secondly, provided directly by the empirical analysis, we showed that there is a model that can help mobilize part of the USD \$3 trillion in treasury funds (according to Compustat 2017 data) currently held by non-financial organizations. Throughout the paper, evidence was presented for a model comprising six variables whose causal interactions are factors for the future success of a mutual collaboration to manage cash surpluses and shortages: expectations of benefits, transparency, trust, management, guarantees and mutual benefit. These factors, for scientifically understanding the events studied, provide an agenda for the implementation of this model at companies. A prerequisite for implementing this model center is that two or more companies should have treasuries with sufficient complementarity to enable them to obtain future benefits; the participants must also be able to visualize those benefits. These circumstances are necessary but not in themselves sufficient: additional variables are required not only on the part of the participating firms but also on that of the system. For firms, those variables include transparency (logically with positive information on the standard of management and results); for the system, they include professionalism in management of the system itself and guarantees to cover potential risks (considered as moderator variable). Trust, 
which is the core for the system, acts both as a facilitator (causal variable) for the commencement of the process (willingness to collaborate) and a result variable (dependent variable) for the quality of the system itself and the guarantees that are provided. This generates a virtuous circle (positive loop) that enables a collaborative and sustainable cash system to be implemented. In short, for a model process to begin, there must be complementarity of treasuries, a certain level of trust between participating firms, and positive expectations concerning the quality and guarantees of the management system proposed. If these conditions are met, a group of companies, or a single driver company, can set up the proposed model. The model cannot be used for managing all the cash in this system, but it is an alternative for partial solutions for cash surpluses and shortages. This model represents different options in the collaborative economy that can be transferred to the field of business, as we established that at least in this case, there are six criteria for creating collaboration between organizations in treasury management, aligning long-term goals, with professionalized in-house management, and probably the use of networks.

The main limitations of our study is that the sample used was restricted to Spain, so the method cannot initially be standardized directly across European or international contexts. The model established the factors to manage cash mutually based on some cases, reinforced by experts' support, and tested by empirical answers of financial professionals; however, it remains to be established if the model could be efficient and to what degree. This was not the aim of our paper, but could be an area of future research. Microanalysis and macroanalysis could provide some evidence about how this type of system could affect financial intermediation as a whole. Finally, during the crisis, treasury levels have been the main concern of many firms-as remains the case in Spain-but there is now an overall treasury surplus. This may restrict collaboration between organizations because the collaboration cash sharing model success is based on a balance between positive and negative treasury levels in groups. Optimization occurs in the long-term, which means that it is possible to meet treasury needs during times of crisis.

Finally, these results suggest that this new concept of treasury management may give rise to a large number of widely varying lines of research, the most immediate of which seems initially to be concerned with efficiency. The extent to which this model is efficient compared with existing models needs to be determined from the viewpoint of individual firms and from that of the ecosystem of firms in a model. This research needs to incorporate outputs concerned with efficiency with a broader scope than just treasury affairs or their profitability; for instance, the research could be extended to the value added to the ecosystem, changes in risks of non-payment, the volume of relational operations generated, the quality of financial structures, and the level of moral risk involved.

\section{Conclusions}

The possibility of the existence of shared treasury management has been demonstrated by the existence of specific cases; the development of the model to jointly manage treasuries is not subject to analysis at this stage. Thus, the main contribution this work was identifying the variables and the causal relationships involved in collaborative treasury management, called the cash-sharing model. Along this line, the following factors were identified as being necessarily involved in the beginning of sharing process: trust, expectations, guarantees, and transparency. The quality of management and mutual benefit would be necessary for the sustainability of the model over time.

Although the model starts with the expectation of mutual benefits of the participants, the central core on which it is based is trust. As a result, a value usually considered as intangible is a key factor in the possibility of initiating a collaborative model among several companies. Guarantees and transparency, in this order, are significant factors of trust.

The results of this research can help companies that arise, either by necessity or philosophy, to start collaborative processes in treasury management with customers or suppliers. This work provides a reference model to develop this cash-sharing system with greater guarantees than those from intuitions or the analysis of previous experiences. 
The limitations of this study include the chosen methodology and the questionnaires, especially when they refer to a topic about which the researchers have little experience. The answers may be only opinions that do not necessarily reflect attitudes and do not sufficiently account for possible transaction costs or risks.

Possible future lines of research include the possibility of using experimental methodology to contrast the role of different variables in this context, especially trust, which is well-suited to this type of treatment.

Author Contributions: All authors jointly worked on deriving the results and wrote the paper. All authors have read and approved the final manuscript.

Funding: This research was funded by University of the Basque Country UPV/EHU, (US17/24 grant number) and FESIDE foundation.

Acknowledgments: We thank the anonymous referees for their useful suggestions.

Conflicts of Interest: The authors declare no conflict of interest.

\section{Appendix A}

Table A1. Questions of the questionnaire base on a Likert scale.

\begin{tabular}{|c|c|}
\hline & EXPECTATIONS (E) \\
\hline \multicolumn{2}{|c|}{$\begin{array}{c}\text { For there to be positive expectations of a collaborative relationship in treasury management between a group of } \\
\text { organizations there must be: }\end{array}$} \\
\hline 1 SYNERGIES & Potential treasury synergies between the organizations involved \\
\hline 2 CYCLESCOM & Complementarity in positive and negative treasury cycles \\
\hline 3 DATACOM & Complementarity in the accrual dates of payments in and out. \\
\hline 4 SAVE & A prior quantification of the savings/benefits that this would entail for each organization. \\
\hline 5 NETCOST & A reduction in costs compared to conventional funding from banks. \\
\hline 6 COMBENEFIT & Expectations of benefits other than financial profit. \\
\hline \multicolumn{2}{|r|}{ TRUST (TRU) } \\
\hline \multicolumn{2}{|c|}{$\begin{array}{l}\text { For there to be sufficient trust for a collaborative treasury management system to be set up by a group of } \\
\text { organizations the organizations taking part: }\end{array}$} \\
\hline 7 MANAGSIST & Must have good day-to-day and top management systems. \\
\hline 8 POSITVALUE & Must rate the other organizations positively. \\
\hline 9 REJECTOPORT & Must avoid any kind of opportunistic behavior. \\
\hline 10 PREDISPOSITION & Must show a predisposition to trust the rest of the organizations. \\
\hline 11 POSTPONE & Must be willing to postpone present results in exchange for future benefits. \\
\hline 12 SKILLSMNG & Must have competent, honest management teams. \\
\hline \multicolumn{2}{|c|}{ TRANSPARENCY (TRA) } \\
\hline \multicolumn{2}{|c|}{$\begin{array}{c}\text { To increase the transparency of the collaborative treasury management system for a group of organizations, the } \\
\text { organizations taking part: }\end{array}$} \\
\hline 13 FULLINFO & Must provide full information on the values and competencies of their top management. \\
\hline 14 ACCURATEINFO & Must provide real-time information on their economic and financial situations. \\
\hline 15 IRISK & Must immediately disclose any risk that they may have incurred. \\
\hline 16 GRIMEM & Must publish sustainability reports in GRI format or similar. \\
\hline 17 PANEL & Must facilitate access to their scorecards of management indicators. \\
\hline 18 CASHPLAN & Must provide up-to-date information on the degree of fulfillment of their treasury plans. \\
\hline \multicolumn{2}{|r|}{ GUARANTEES (G) } \\
\hline \multicolumn{2}{|r|}{ For a collaborative treasury management system to work it is necessary: } \\
\hline 19 LIQUIDITY & For the system to have sufficient liquidity to cater for any eventuality. \\
\hline
\end{tabular}


Table A1. Cont.

\begin{tabular}{|c|c|}
\hline \multicolumn{2}{|r|}{ EXPECTATIONS (E) } \\
\hline 20 REAL & For there to be a system of real guarantees that can offset the risks incurred. \\
\hline 21 CASHPER & For the volume of treasury funds involved to be only a small percentage of the total. \\
\hline 22 NOOPPORT & For the system to be ring-fenced against opportunist moves by its members. \\
\hline 23 NORMATIVE & For regulations to be set up to govern it. \\
\hline 24 RISKSIM & For there to be symmetry in risks between the organizations taking part. \\
\hline & MANAGEMENT (MA) \\
\hline \multicolumn{2}{|r|}{ For a collaborative treasury management system to work it is necessary: } \\
\hline 25 EFFICIENCY & For the organizations taking part to have efficient management systems. \\
\hline 26 BENEFCOST & $\begin{array}{c}\text { For the cost of management to be no more than a small percentage of the gross benefits } \\
\text { obtained. }\end{array}$ \\
\hline 27 COSTCOMP & $\begin{array}{c}\text { For the cost of managing the system to be lower than the cost of managing alternative } \\
\text { financing systems. }\end{array}$ \\
\hline 28 INFOSIM & For there to be symmetry of information concerning management. \\
\hline 29 CONTROL & For there to be suitable management control mechanisms to enable risks to be anticipated. \\
\hline 30 CONTINGPLAN & $\begin{array}{l}\text { For there to be contingency plans for dealing with potential errors and unforeseen } \\
\text { circumstances. }\end{array}$ \\
\hline \multicolumn{2}{|r|}{ MUTUAL BENEFIT (MB) } \\
\hline \multicolumn{2}{|r|}{ For a collaborative treasury management system to be accepted it is necessary: } \\
\hline 31 NOECONBENE & $\begin{array}{l}\text { For there to be benefits other than financial profits, e.g., strategic or procurement benefits, } \\
\text { new markets, loyalty in relationships, etc. }\end{array}$ \\
\hline 32 TOTALBENEFIT & For all the organizations taking part to benefit. \\
\hline 33 BENEFITINDEX & For there to be indicators capable of quantifying the benefits obtained on a regular basis. \\
\hline 34 PREVFUTURBEN & For there to be expectations that benefit will be maintained in the future. \\
\hline 35 VERIFYBEN & For there to be the prospect of immediate benefits. \\
\hline 36 SYMMETRYBEN & $\begin{array}{l}\text { For there to be some symmetry in the benefits obtained by the different organizations } \\
\text { taking part. }\end{array}$ \\
\hline
\end{tabular}

\section{References}

Arouri, Mohamed, and Guillaume Pijourlet. 2017. CSR Performance and the Value of Cash Holdings: International Evidence-PhilPapers. Available online: https://philpapers.org/rec/AROCPA (accessed on 24 February 2019).

Bardhi, Fleura, and Giana M. Eckhardt. 2012. Access-based consumption: The case of car sharing. Journal of Consumer Research 39: 881-98. [CrossRef]

Belk, Russell. 2014. You are what you can access: Sharing and collaborative consumption online. Journal of Business Research 67: 1595-600. [CrossRef]

Beraza, Ana, Leire San-Jose, and Jose L. Retolaza. 2016. The Mutual Holding Cash: Towards a collaborative proposal cash management. Management International 21: 101-13. [CrossRef]

Blakstad, Sofie, and Robert Allen. 2018. FinTech Revolution. Cham: Springer International Publishing, ISBN 978-3-319-76013-1.

Bollen, Kenneth, and Richard Lennox. 1991. Conventional wisdom on measurement: A structural equation perspective. Psychological Bulletin 110: 305-14. [CrossRef]

Botsman, Rachel, and Roo Rogers. 2010. What's Mine Is Yours: The Rise of Collaborative Consumption. New York: HarperBusiness.

Bushman, Robert M., Joseph D. Piotroski, and Abbie J. Smith. 2004. What Determines Corporate Transparency? Journal of Accounting Research 42: 207-52. [CrossRef]

Chang, Howard F. 2000. A Liberal Theory of Social Welfare: Fairness, Utility, and the Pareto Principle. The Yale Law Journal 110: 173-235. [CrossRef] 
Cheung, Adrian. 2016. Corporate social responsibility and corporate cash holdings. Journal of Corporate Finance 37: 412-30. [CrossRef]

Cohen, Boyd, and Jan Kietzmann. 2014. Ride On! Mobility Business Models for the Sharing Economy. Organization E Environment 27: 279-96. [CrossRef]

Comelli, Michael, Pierre Féniès, and David Lemoine. 2009. Tactical planning for optimal cash flow and value sharing in supply chain. International Journal of Logistics Systems and Management 5: 323-43. [CrossRef]

Custódio, Cláudia, and Daniel Metzger. 2014. Financial expert CEOs: CEO's work experience and firm's financial policies. Journal of Financial Economics 114: 125-54. [CrossRef]

Diamantopoulos, Adamantios, and Heidi M. Winklhofer. 2001. Index construction with formative indicators: An alternative to scale development. Journal of Marketing Research 38: 269-77. [CrossRef]

Douglas, Susan P., and C. Samuel Craig. 2009. Advances in International Marketing. Edited by Jörg Henseler, Christian M. Ringle and Rudolf R. Sinkovics. Bingley: Emerald Group Publishing, vol. 20, ISBN 978-1-84855-468-9.

Duchin, Ran, Thomas Gilbert, Jarrad Harford, and Christopher Hrdlicka. 2017. Precautionary Savings with Risky Assets: When Cash is Not Cash. The Journal of Finance 72: 793-852. [CrossRef]

Dudley, Evan, and Ning Zhang. 2016. Trust and corporate cash holdings. Journal of Corporate Finance 41: 363-87. [CrossRef]

Eggert, Andreas, and Sabrina Helm. 2003. Exploring the impact of relationship transparency on business relationships A cross-sectional study among purchasing managers in Germany. Industrial Marketing Management 8. [CrossRef]

Ertz, Myriam, and Sébastien Leblanc-Proulx. 2018. Sustainability in the collaborative economy: A bibliometric analysis reveals emerging interest. Journal of Cleaner Production 96: 1073-85. [CrossRef]

Fatemi, Ali M., and Iraj J. Fooladi. 2013. Sustainable finance: A new paradigm. Global Finance Journal 24: 101-13. [CrossRef]

Gefen, David, and Detmar W. Straub. 2004. Consumer trust in B2C e-Commerce and the importance of social presence: Experiments in e-Products and e-Services. Omega 32: 407-24. [CrossRef]

Gounaris, Spiros P. 2005. Trust and commitment influences on customer retention: Insights from business-to-business services. Journal of Business Research 58: 126-40. [CrossRef]

Hair, Joe F., Christian M. Ringle, and Marko Sarstedt. 2011. PLS-SEM: Indeed a Silver Bullet. Journal of Marketing Theory and Practice 19: 139-52. [CrossRef]

Hamari, Juho, Mimmi Sjöklint, and Antti Ukkonen. 2016. The sharing economy: Why people participate in collaborative consumption. Journal of the Association for Information Science and Technology 67: 2047-59. [CrossRef]

Hogan, John E. 2001. Expected Relationship Value. Industrial Marketing Management 30: 339-51. [CrossRef]

Inkpen, Andrew C., and Steven C. Currall. 1988. The nature, antecedents, and consequences of joint venture trust. Journal of International Management 4: 1-20. [CrossRef]

John, Nicholas A. 2013. The social logics of sharing. The Communication Review 16: 113-31. [CrossRef]

Kalmi, Panu. 2017. The Role of Stakeholder Banks in the European Banking Sector. In Institutional Diversity in Banking. Palgrave Macmillan Studies in Banking and Financial Institutions. Cham: Palgrave Macmillan, pp. 33-50. ISBN 978-3-319-42072-1.

Lamberton, Geoff. 2005. Sustainability accounting-A brief history and conceptual framework. Accounting Forum 29: 7-26. [CrossRef]

Lamberton, Cait Poynor, and Randall L. Rose. 2012. When is ours better than mine? A framework for understanding and altering participation in commercial sharing systems. Journal of Marketing 76: 109-25. [CrossRef]

Lamming, Richard, Nigel Caldwell, and Deborah Harrison. 2004. Developing the Concept of Transparency for Use in Supply Relationships. British Journal of Management 15: 291-302. [CrossRef]

Li, Yuting, Tong Chen, and Baogui Xin. 2016. Optimal financing decisions of two cash-constrained supply chains with complementary products. Sustainability 8: 429. [CrossRef]

Liu, Chenxi. 2016. Earnings Transparency and Corporate Cash Holdings by Chenxi SSRN. Annual Meeting Conference. Available online: https:/ / papers.ssrn.com/sol3/papers.cfm?abstract_id=2824898 (accessed on 24 February 2019). 
Locorotondo, Rosy, Nico Dewaelheyns, and Cynthia Van Hulle. 2014. Cash holdings and business group membership. Journal of Business Research 67: 316-23. [CrossRef]

MacKenzie, Scott B., Philip M. Podsakoff, and Nathan P. Podsakoff. 2011. Construct measurement and validation procedures in MIS and behavioral research: Integrating new and existing techniques. MIS Quarterly 35: 293-334. [CrossRef]

Madhok, Anoop, and Stephen B. Tallman. 1998. Resources, Transactions and Rents: Managing Value Through Interfirm Collaborative Relationships. Organization Science 9: 326-39. [CrossRef]

McEvily, Bill, and Marco Tortoriello. 2011. Measu.ring trust in organisational research: Review and recommendations. Journal of Trust Research 1: 23-63. [CrossRef]

McKnight, D. Harrison, Vivek Choudhury, and Charles Kacmar. 2002. Developing and Validating Trust Measures for e-Commerce: An Integrative Typology. Information Systems Research 13: 334-59. [CrossRef]

Moodys US Corporate Cash Pile. 2007. Led by Tech Sector, to Grow to $\$ 1.77$ Trillion by End of 2016. (20 November 2017). Available online: https:/ / www.moodys.com/research/Moodys-US-corporate-cash-pile-to-rise-5to-19--PR_375739 (accessed on 28 June 2018).

Morgan, Robert M., and Shelby D. Hunt. 1994. The commitment-trust theory of relationship marketing. Journal of Marketing 58: 20-38. [CrossRef]

Pavlou, Paul A. 2003. Consumer acceptance of electronic commerce: Integrating trust and risk with the technology acceptance model. International Journal of Electronic Commerce 7: 101-34.

Pavlou, Paul A., and David Gefen. 2004. Building effective online marketplaces with institution-based trust. Information Systems Research 15: 37-59. [CrossRef]

Pirson, Michael, and Deepak Malhotra. 2011. Foundations of Organizational Trust: What Matters to Different Stakeholders? Organization Science 22: 1087-104. [CrossRef]

Preston, Lee E., and Douglas P. O'bannon. 1997. The Corporate Social-Financial Performance Relationship: A Typology and Analysis. Business \& Society 36: 419-29. [CrossRef]

Rawlins, Brad. 2008. Give the Emperor a Mirror: Toward Developing a Stakeholder Measurement of Organizational Transparency. Journal of Public Relations Research 21: 71-99. [CrossRef]

Ringle, Christian M., Sven Wende, and Jan-Michael Becker. 2016. SmartPLS 3. Bönningstedt: SmartPLS.

San-Jose, Leire. 2009. Finance \& Common Good/Bien Commmun (Financial Ethics Review-Revue d'Ethique Financiere). Paris: De Boeck Supérieur, pp. 58-68.

San-Jose, Leire, and José L. Retolaza. 2016. Contabilidad Social Orientada a los Stakeholder: Perspectiva de la Administración Pública. Madrid: Piramide.

Schnackenberg, Andrew K., and Edward C. Tomlinson. 2016. Organizational Transparency: A New Perspective on Managing Trust in Organization-Stakeholder Relationships. Journal of Management 42: 1784-810. [CrossRef]

Schor, Juliet B., and Connor J. Fitzmaurice. 2014. Collaborating and connecting: The emergence of the sharing economy. In Handbook of Research on Sustainable Consumption. Cheltenham: Edward Elgar Publishing, pp. 410-25.

Seppänen, Risto, Kirsimarja Blomqvist, and Sanna Sundqvist. 2007. Measuring inter-organizational trust-A critical review of the empirical research in 1990-2003. Industrial Marketing Management 36: 249-65. [CrossRef]

Shaheen, Susan A., and Adam P. Cohen. 2007. Growth in Worldwide Carsharing: An International Comparison. Transportation Research Record: Journal of the Transportation Research Board 1992: 81-89. [CrossRef]

Söllner, Matthias, and Jan Marco Leimeister. 2010. Did they all get it wrong? Towards a better measurement model of trust. Paper presented at Academy of Management Annual Meeting, Montréal, QC, Canada, August 6-10.

Soppe, Aloy. 2004. Sustainable Corporate Finance. Journal of Business Ethics 53: 213-24. [CrossRef]

Tussyadiah, Iis P. An Exploratory Study on Drivers and Deterrents of Collaborative Consumption in Travel. In Information and Communication Technologies in Tourism 2015. Edited by Tussyadiah Iis and Inversini Alessandro. Cham: Springer International Publishing, pp. 817-30. ISBN 978-3-319-14342-2.

Whipple, Judith M., Stanley E. Griffis, and Patricia J. Daugherty. 2013. Conceptualizations of Trust: Can We Trust Them? Journal of Business Logistics 34: 117-30. [CrossRef]

Zervas, Georgios, Davide Proserpio, and John W. Byers. 2017. The Rise of the Sharing Economy: Estimating the Impact of Airbnb on the Hotel Industry. Journal of Marketing Research 54: 687-705. [CrossRef]

(C) 2019 by the authors. Licensee MDPI, Basel, Switzerland. This article is an open access article distributed under the terms and conditions of the Creative Commons Attribution (CC BY) license (http:/ / creativecommons.org/licenses/by/4.0/). 